\title{
المساندة الاجتماعية لدى الأطفال
}

\author{
إعراد \\ الباحثة/ نورا احمد حسين عبد الرحمن
}

إشراف

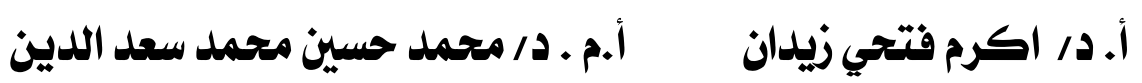

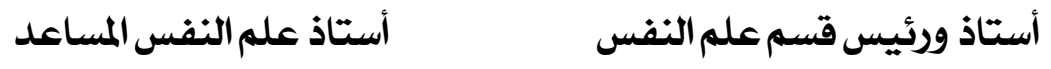

$$
\begin{aligned}
& \text { كليتا الآداب جامعتشائنصورة }
\end{aligned}
$$

المجلت العلميت لكليت التربيت للطفولت المبكرة ـ جامعت المنصورة

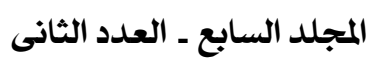

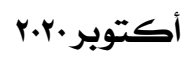

العدد الثانى : أكتوبر •r.r

المجلد السابع 


\section{المساندة الاجتماعية للدى الأطفال}

* نورا احمد حسين عبد الرحمن

\section{مفهوم المساندة الاجتماعية: -}

تعتبر المساندة الاجتماعية باختلاف أنماطها ومصادر ها مــصدر حيـوي

ومستمر من مصادر الدعم النفسي والاجتماعي، كما تعتبر مصدر من مــصادر

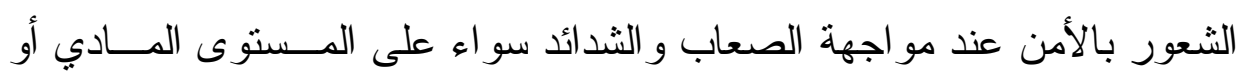
المعنوي أو مو اجهة أحداث الحياة الضاغطة و انعكاس كل مما سبق على الجانب الصحي وهنا تكون الحاجة للمساندة في أوجها. (محمد الشناوي و عبد الــرحمن، . (r:) $99 \varepsilon$

وترجع جذور مفهوم المساندة الاجتماعية إلى علما الاجتماع حيث تتاولو ا

هذا المفهوم في إطار اهتماماتهم بالعلاقات الاجتماعية، عندما قدمو ا مفهوم شبكة

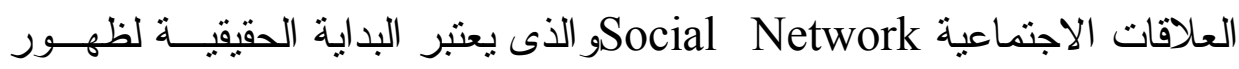

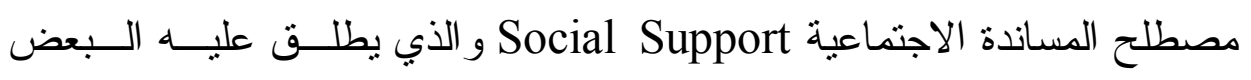
Social Resources مسمى الموارد الاجتماعية

بينما يحدده البعض الآخر علــى أنـــهـ إمــدادات اجتماعيــة ( Social ) وتعتمد المساندة فـي تقــدير ها علــى إدر الك الافــر اد لــشبكاتهم

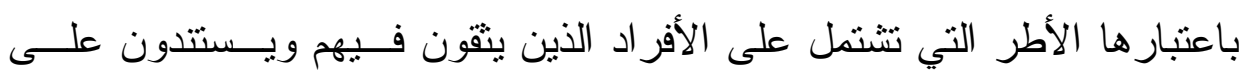
علاقاتهم بهم (محمد الثناوي و عبد الرحمن، ؟ 99 (:ب).

* باحثت ماجستير

r.r. العدد الثانى : أكتوبر

rAq

المجلد السابع 
وتعرف المساندة الاجتماعية بانها درجة شعور الفرد بتــوافر المـشـاركة

العاطفية، و المساندة المادية و العملية من جانب الاخرين مثل (الاسرة، و الاقارب،

و الاصدقاء، وزملاء العمل، ورؤساء العمل)، وكــللك وجــود مــن يزودونـــهـ

بالنصيحة و الارشّاد من هؤلاء الأفر اد، ويكون معهم علاقات اجتماعيـــة عميقـــة

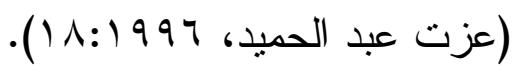

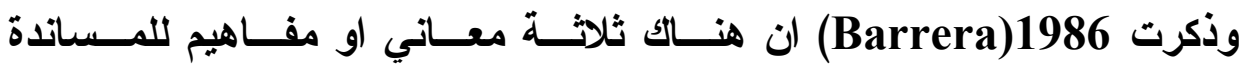
الاجتماعية وهي:

Social Embedded أل)-الغمر الاجتماعي

وفقا لهذا المفهوم فإن المساندة الاجتماعية تشير إلى العلاقات والــرو ابط

الاجتماعية التي يقيمها الافر اد مع الاخرين ذوي الاهمية في بيئتهم الاجتماعية.

Perceived Social Support اب) - المساندة الاجتماعية المدركة

وينظر للمساندة الاجتماعية وفقا لهذا المعنى باعتبار هـــا تقويمــا معرفيــا

$$
\text { للعلاقات الثابتة مع الآخرين. }
$$

\section{Support Enacted (ج) - المساندة الفعلية}

ويشير هذا المفهوم الى المساندة الاجتماعية باعتبارها تلك الافعال التـي

يؤديها الآخرون بهدف مساعدة شخص معين (شعبان جاب الله، عــادل محمــد،

$$
\cdot(r \cdot): \wedge 0
$$

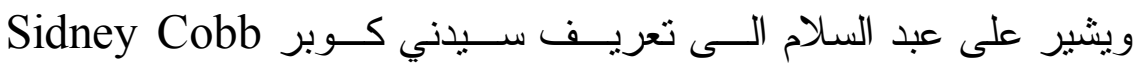

للمساندة الاجتماعية على انها تقوم على الرعاية المتبادلة بين الافر اد (التو اصــل

$$
\text { الاجتماعي) ونتسم بثلاث مقومات أساسية هي: }
$$


أ- المساندة الوجدانية Emotional Support

وتتمنل في تسليم الفرد بانه محاط بالرعاية و لاحب من قبل الجماعة التي

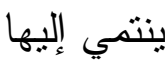

بـ المساتدة المدعمة بالاحترام Esteem Support وهي التي تقود إلى إحساس الفرد بالاحتر ام والقيمة بين المحيطين به

ج-المساتدة المدعمة من شبكة العلاقات الاجتماعية Network Support

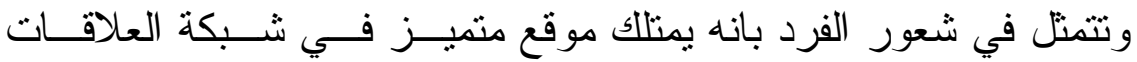

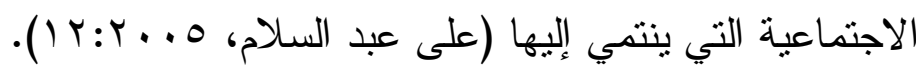

حيث يرى خان (Kahn) ان المساندة الاجتماعية لها ثلاث مقومات هامة

هي العاطفة و التفاعل وتقديم العون او المساعدة وبهذا يعـرف خــان المـساندة

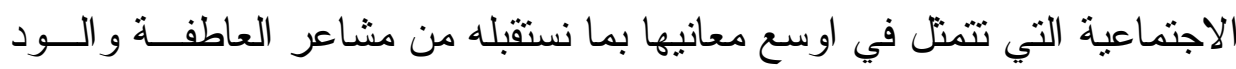
و الحب وتعبيرات القبول و المبادرة في تقديم المساعدة المباشرة او العون المادي

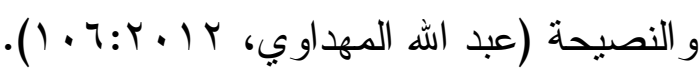

ويعرفها (على عبدالسلام، ه . ץ:ז () بانها درجة شعور الفرد بتــوافر المشاركة العاطفية، و المساندة المادية و العملية من جانب الآخرين، مثل الاســـرة، و الاقارب، و الاصدقاء وزملاء العمل وكذللك وجود مسـن يزودونــهـ بالنـصيحة

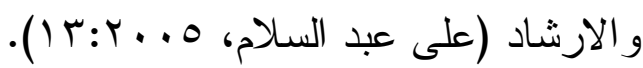

بينما يـرى (سار اســون و اخــرون (Sarason\& al(1986) المسـساندة الاجتماعية: بانها الاعتقاد بوجود بعض الاتشخاص الذين بمكن للفرد أن بثق بهر الهر

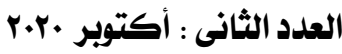


و الذين بتركون لديه انطباع بأنهم يحبونه ويقدرونه ويمكن اللجو إليهم و الاعتماد

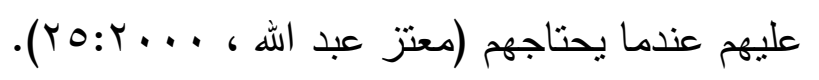

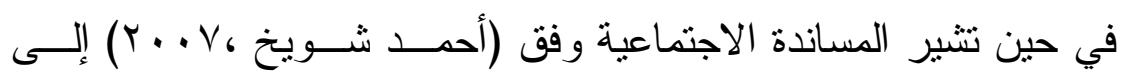

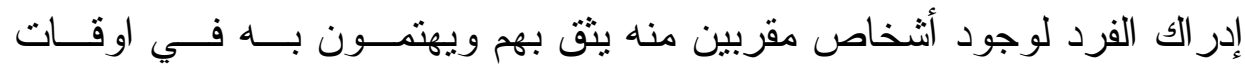

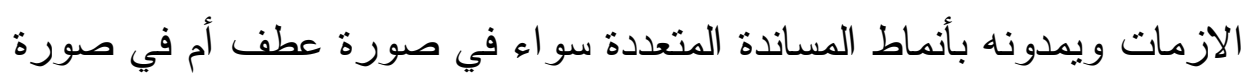

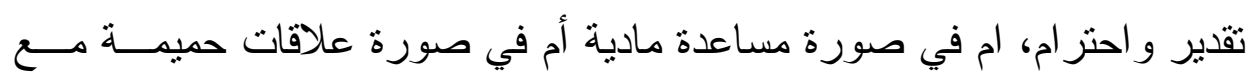

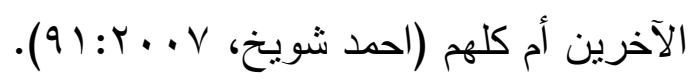

ويرى هوس (House) ان المساندة الاجتماعية تـشير الـى العلاقــات

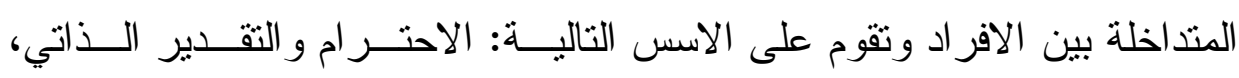

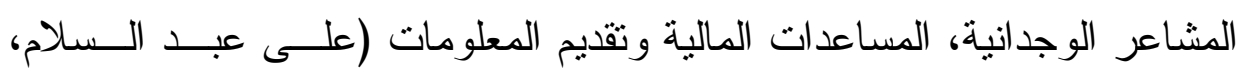

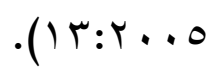

ويرى كابلان (Caplan,1981) ان المساندة الاجتماعية هي ذلك النظام

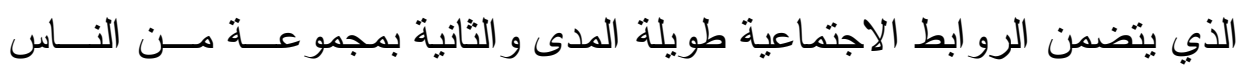

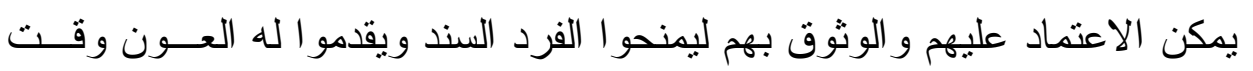

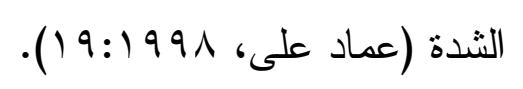

ويرى (معتز عبد الله ، ... ب) المساندة الاجتماعية بأنها الاعتقاد بوجود بعض الاثخاص الذين يمكن للفرد أن يثق فيهم ضمن شبكة علاقاته الاجتماعية

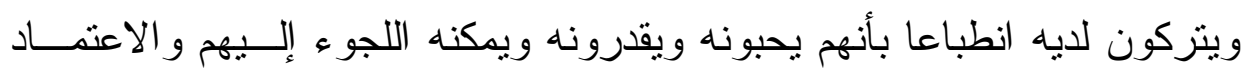

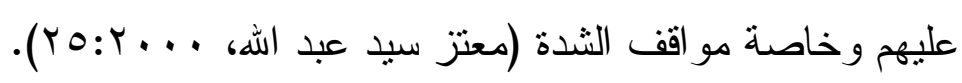

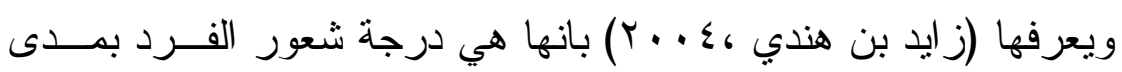

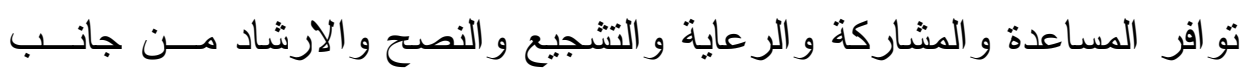

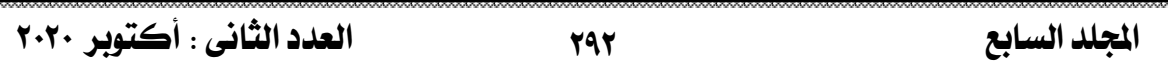


الآخرين (الاسرة، الاقران، الاصدقاء، الزملاء، المعلمـين) وتكــــين علاقــات

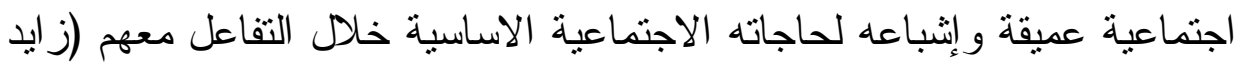
بن هندي، ع . . 9:4).

ويعرفها (شعبان جاب الله، عادل هريدى، ـ. ب) بأنها مقدار ما يتلةــاه

الفرد من دعم وجداني ومعرفي ومادي من خلال الاخرين في بيئته الاجتماعيــة عندما تحدث أحداث أو مو اقف يمكن ان تثير المشقة لديه (ثــعبان جـاب الله،

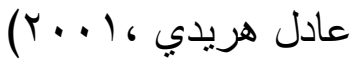

وفى هذا السياق ، يرى بعـض البــاحثين (Haley 1996) ان الــدعم

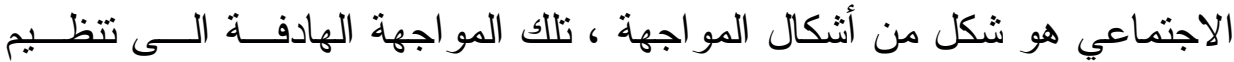

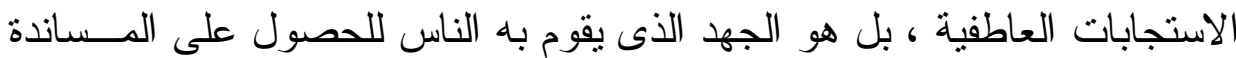
الاجتماعية للتخفف من الوضع الضاغط ومن آثاره ، فالبحث عن دعم اجتماعي

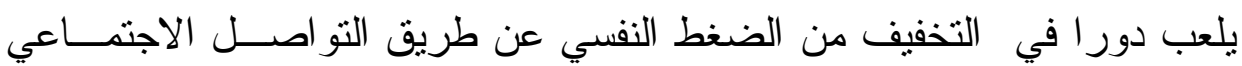

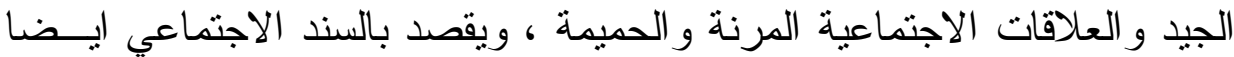
شعور الفرد بانه شخص محبوب ومقبول اجتماعيا ومرغوب فيه و انه ينتمى الى الى شبكة دعم اجتماعية نقدم له الــدعم المــادي و الانفعـالي (العــاطفي ) الــلازم

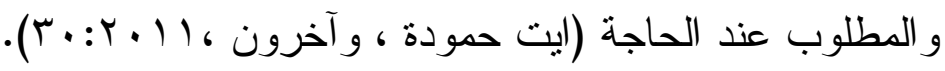

كما عرف (محمد خليل ،997 199) المساندة الاجتماعية بانها كـل دعــ مادي او معنوي يقدم للمريض بقصد رفع روحه المعنويــة ومسـساعدته علـى لـى محاربتهم للمرض وتخفيف آلامه العضوية و النفسية الناجمة عن المرض (محمد بيومي خليل،

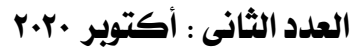


وتعرف المساندة الاجتماعية بأنها " الاساليب المـسـاعدة المختلفــة التــي

يتلقاها الفرد من أسرته أو أصدقائه، و التي تتمثل في تقديم الرعاية الاجتماعيــة و التوجيه و الاهتمام و النصـح و التشجيع في كافة المو اقف، و التي تـشبع حاجتــهـ المادية و الروحية للقبول و الحب و الثعر بالأمان فتجعله يثق بنفسه ويدركها الفرد

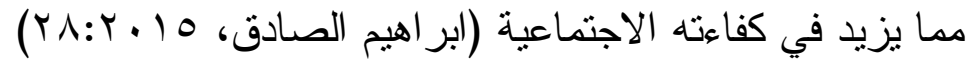
وبصرف النظر عن مختلف التوجهات النظرية التـي عرفــت المـساندة الاجتماعية وما يمكن ان يوجد بها من اختلاف، فإن هنالك اتفاقا على ان مفهـوم المساندة الاجتماعية يشمل مكونين أساسيين: الاول أن يدرك الفرد أنه يوجد عدد كاف من الاشخاص في شبكة علاقاته الاجتماعية يمكن الرجوع إليهم و الاعتماد عليهم عند الحاجة و الثاني أن يكون لدى الفرد درجة معقولة من الرضـــا عــن

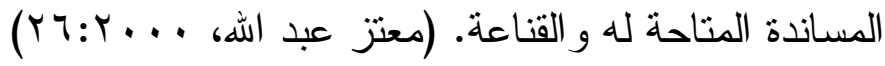

و انطلاقا مما تقدم يمكن تعريف المساندة الاجتماعية إجر ائيا في الدر اســـة الحالية بانها إدر الك الفرد انه يوجد عدد كافي من الاشخاص في حياته يمكـن ان يرجع إليهم عند الحاجة طلبا للمساعدة و الدعم منل الاسرة و الاصدقاء و الاقارب و الجير ان و غير هم، و ان يكون لدى هذا الفرد درجة من الرضا عن هذه المساندة

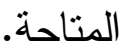

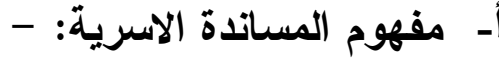

المساندة الاسرية تعنى الحصول علــى العــون و المـسـاعدة مــن قبـلـل

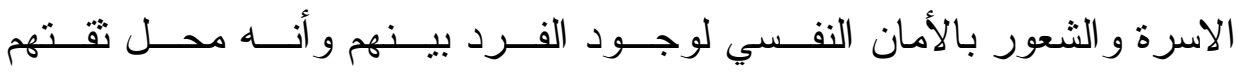
و احتز امهم. 


$$
\text { ب- مفهوم المساندة من الاصدقاء: - }
$$

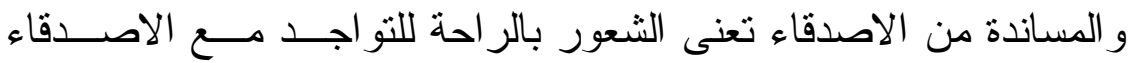

ومشاركتهم اهتمامات الحياة و الحصول على المناصرة و المساعدة عند الضرورة

$$
\text { (محمد محروس، محمد السيد، \& } 99 \text { (:Y \&). }
$$

إلى ان علماء نفس الصحة أكدو اعلى ان المساندة تعد من الموضــوعات الهامة التي يجب در استها من الناحية الوظيفية لدى مرضى الاور ام الـسرطانية وأرجعو ا ذلك إلى سبينين و اضحين هما:

ا - ان البيئة الاجتماعية للمريض تمنل درعا واقيا له من التأثنيرات الــضارة للمشقة المصاحبة للإصـابة بمرض السرطان، كما وجــدوا ان الاثــكال البنائية لشبكة العلاقات الاجتماعية للفرد، منل حجم العلاقـات و الاثــكال الوظيفية كالمساندة الوجدانية، ترتبط بمعدلات الوفاة و البقاء لدى مرضــى

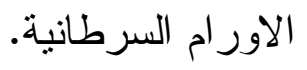

r- من ناحية اخرى تؤثز الاصـابة بمرض الاور ام السرطانية علـى شـــــة العلاقات الاجتماعية للمريض، فلو كان هذا المرض يتصف بانه مــرض مهلك ومميت يجعل اعضاء هذه الشبكة الاجتماعية يبتعدون عن المريض مما يترتب عليه نواتج خطيرة للمريض أقلها عدم حـصوله علــى نمــط

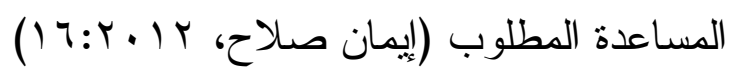

\section{تعريف المساندة الاجتماعية من وجهة نظر الباحثة:}

بانها مقدار ما تدركه المر أة المصابة بسرطان الثذي من رعاية و اهتمــام وحب ونصائح ومعلومات من المحيطين بها من (افــر اد أســرتها، أصـــدقائها، 
زملائها) و الذي سيقدر من خلال الدرجة الكلية التي تتحصل عليها العينة علـىى اداة القياس المصممة لذلك.

\section{اهمية دور المساتدة الاجتماعية: -}

تستطيع المساندة الاجتماعية أن تمد الفرد بخمسة أثنياء مهمة وهي: ا - إمداد الفرد بإحساسه الذاتي Sense of self من قبل الاسرة أو الاخرين

r- إمداد الفرد بالتشجيع و التغذية المرتدة Feedback الايجابية. بـ حماية الفرد من كثير مــن الــضغوط الحياتيـــة Life stress اليوميــة الضاغطة.

عـ الاسهام العالي من المعرفة Knowledge، المهار ات Skills. 0- إمداد الفرد بالفرص الاجتماعية (نورة بنت عبد العزيز ، ؟ ا ـ :9 §). وتلعب المساندة الاجتماعية دور ا هاما أيضا في الصحة النفسية والجسمية بل وفى المرض الجسمي و النفسي أيضا وفى كل مر احل الحياة من الطفولة إلى

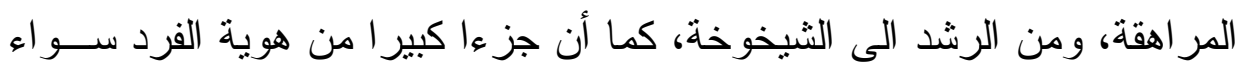

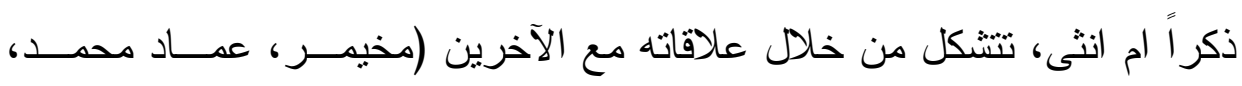
$.(1) 9: 199 \mathrm{~V}$

\section{دور المساندة الاجتماعية مع المرضى:}

تلعب المساندة الاجتماعية من الأسرة و الأصدقاء دوراً هاماً في التـصدي

للشعور بالعجز، فمريض السرطان يعاني من مشاكل نفسية وأسرية و اجتماعيــة خصوصا في الاندماج مع العالم الخارجي، وقد يؤثر هذا على مشاعر الـسعادة

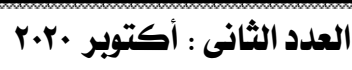


و التكيف النفسي، وقد تكون للمساندة أهمية خاصة في فتــرة المر اهقــة بـسببـ التغير ات الكثيرة التي تحدث داخل وخارج الفرد في هذه المرحلة.

فللمساندة الاجتماعية دور ليس بالقليل إطلاقا، وذلك على اعتبار هذه الفئة من مرضى السرطان، فهي فئة تستحق المساندة الاجتماعية و التدعيم، و لابد من تقديم الدعم النفسي والاجتماعي لهم، عن طريق الآباء والأصدقاء أو المدرسة او الو وله الاشخاص الذين يتعاملون معهم. فالبيئة التي يعيشون فيها و اتجاهات الاشـــاص المحيطين بهم تسهم بدور كبير في مساعدته لأخذ ادو ارهم في المجتمع وتتميــة

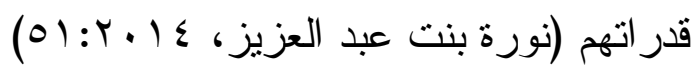
أبعاد المساتدة الاجثماعية: -

يرى (ناجى الخشاب ، Y . . F) ان المساندة النفسية الاجتماعية من الممكن أن تأخذ ثلاثة أشثكال وهي: -

ا - المساندة الذاتية Self-Support

ويقصد بها أي دعم معنوي يستطيع الفرد منحه لنفسه بهدف التخلب علــى المشاكل التي يو اجهها .

r- Social Support المساندة الاجتماعية

ويقصد بها الدعم المعنوي او الإجرائـي الـــي يقــدم مــن المحيطـين

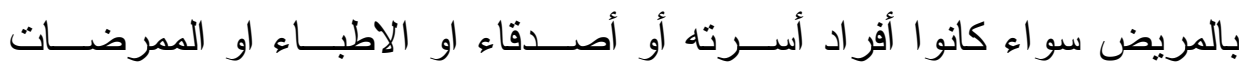
المشرفين عليه في العلاج او المجتمع لمساعدته لتخطى العقبات و المشاكل التـي تو اجهه

r.r. العدد الثانى : أكتوبر 


\section{- Tangible Support المساندة المادية}

ويقصد بها أي دعم مادي بقدم من المحيطين بالمريض و المجتمع بطريق مبانشر أو غير مباثر بهدف مشاركته في التغلب على مشاكله المادية ومسساندته

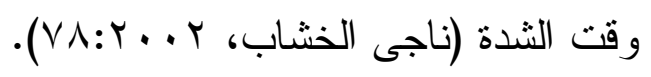

ويرى علماء النفس الاجتماعي ان المساندة الاجتماعية تنقـسم إلــى نــوعين

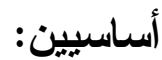

أـ الدعم الوسائلى : ويتضمن مساعدة شخص لآخر بطريقة ملموسة ويشمل هذا إقر اض شخص ما بالمال او مساعدة صديق او مساعدة شخص لديه مشاكل.

بـ الدعم الوجداني: ويتضمن تقديم التتجيع و المشاركة الوجدانية و التقـــير و التفاعل مع الناس بوسائل تدعمه وينظر لكل نوع من انواع المئل المساعدة

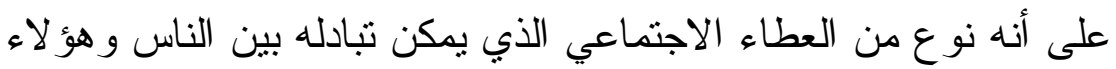

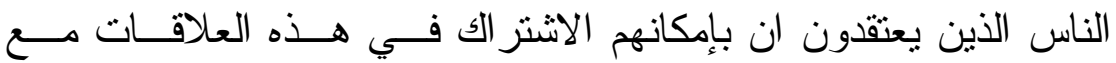

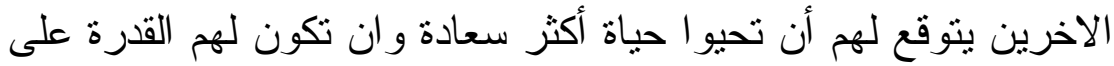

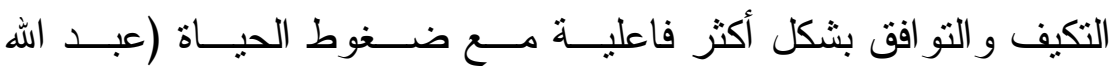

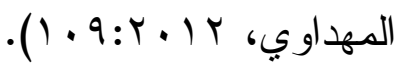

فتوصلت دراسة أفيرى (Alferi,et;2001) و التي أجريت علـى عينــة

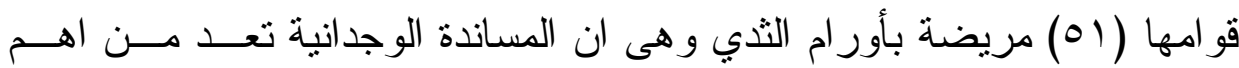

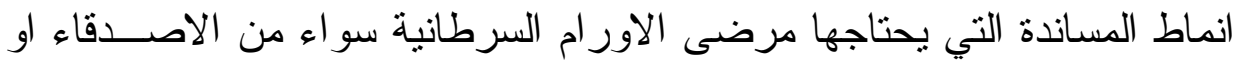

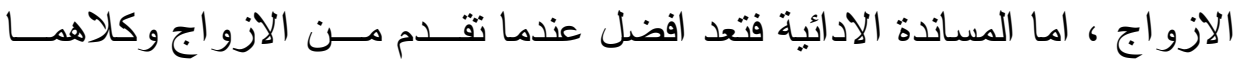

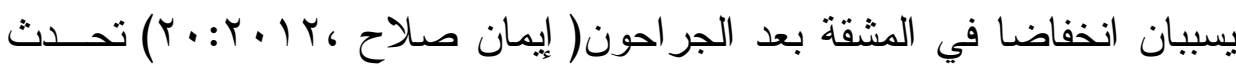


(Scheafer et.al 1981) عن ثلاثة أبعاد للمساندة الاجتماعية هي : المسـاندة

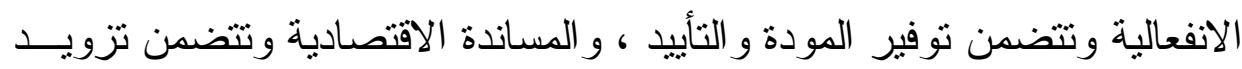

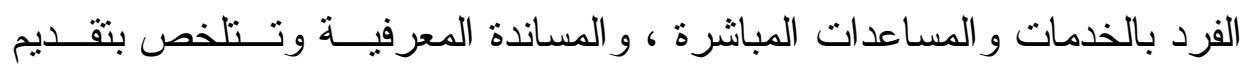
النصائح وتوجيهات تساعد الفرد في حل مشكلاته وتعطيه تغذية راجعــة عـن

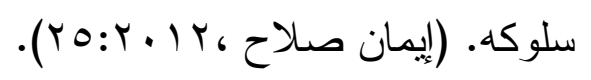

أما (House) فقد أثثار إلى أن المساندة الاجتماعية لهـــا عــدة أثـــكال

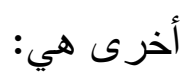

\section{1- المساندة الإفعالية Emotional Support:}

وهي التي تتطوي على الرعاية و التقة و القبول و التعاطف، وتثمل أيضا

التأكيد على الأثز اء الثخصية وتأكيد صحتها ودعم الثقة بالنفس، ومساعدة تقدير الذات، وتسمى أيضا بالمساندة الانفعالية العاطفية.

r المساندة الأدائية Instrumental Support:

و التي تتطوي على العمل و المــساعدة بالمــال، و الخــدمات اللازمـــة، وتخفيف الضغط عن طريق حل المشكلات، و إتاحة بعض الوقت لتلقى الخدمــة و العون ضد أعباء الحياة اليومية، ويطلق عليها اسم المساندة المادية، و المـساندة

$$
\text { الملموسة }
$$

r- المساندة بالمعلومات Information Support:

و التي تتطوي على إعطاء نصائح ومعلومات التعليم مهار ات تؤدى إلـى حل المشكلة او الموقف الضاغط وتقديم المعلومات التي تساعد الفرد على تقيــيم أدائه الثخصي.

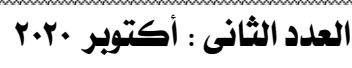


ع - مساندة الأصدقاء Companionship Support:

و التي تتطوي على ما يمكن ان يقدمه الأصدقاء لبعضهم البعض وقـــ

$$
\text { الثدة (عبد الرازق، عماد على، } 991 \text { (:7 (1). }
$$

وترى الباحثة أبعاد المساندة الاجتماعية فيما يلي:

\section{1- المساندة العاطفية Emotional Support:}

و هي كل ما يمكن ان يقدم الزوج و الأسرة و الأصدقاء و الجير ان وزملاء

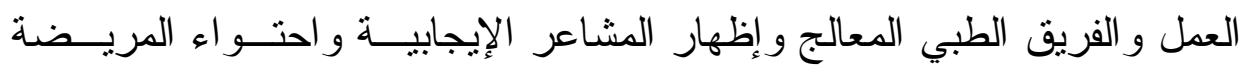

$$
\text { و الر عاية و الاهتمام بها. }
$$

\section{r- Cognitive Support المساندة المعرفية}

وهي مساعدة المريضة في تقديم المعلومات الخاصة بطبيعــة المــرض

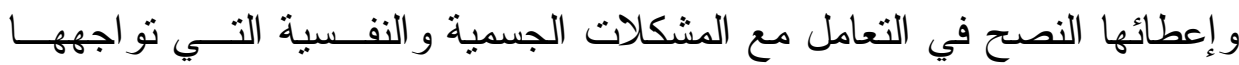
ومساعدتها على التعايش مع مشكلاتها الصحية و الثخصية.

* مصادر المساندة الاجتماعية:

نجد أن المساندة الاجتماعية تختلف باختلاف المرحلة العمرية التي يمــر

بها الفرد. ففي مرحلة الطفولة تكون المساندة متمنلة فـي الاســرة (الأم والأب و الأثقاء)، وفى مرحلة المر اهقة تتمثل المساندة الاجتماعية في جماعات الرفـاق و الاسرة، وفى مرحلة الرشد تتمثل المساندة فـي الــزوج او الزوجــة وكـذللك

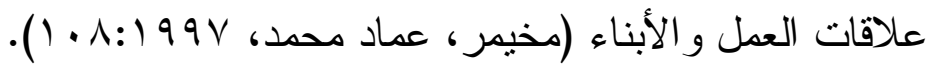




$$
\text { الأول: المصدر غير الرسمي: }
$$

و هو المصدر الذى يُحصله الفرد من الأسرة ، الأصدقاء ، وملاء الاراسة

$$
\text { و العمل ورجال الدين ،و الجيران )عندما يحتاج للمساعدة. }
$$

$$
\text { الثاني: المصدر الرسمي: - n }
$$

و هو المصدر الذي يحصل منه الفرد على المساندة من المتخصصين مثل

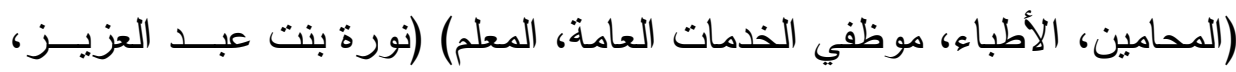

$$
.(0): r \cdot 1 \varepsilon
$$

و اتفق كثير من الباحثين مثـل (Cochran,1990)،(Maguire.1991)

على أن هناك مصدرين للمساندة الاجتماعية هم

• النماذج الرئيسية لتفسير الدور الذي تقوم به المساندة الاجتماعية:

قدم (كو هين وويلز 910 (1) در استة استعرض فيها نتــائج البحــوث التــي

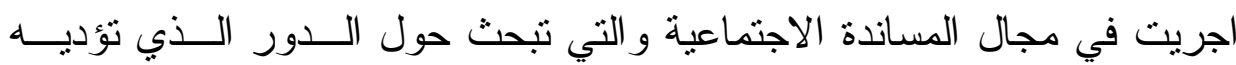

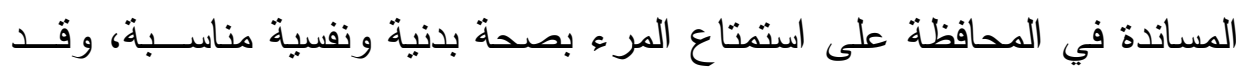
لخص الباحثنان إلى ان هناك نموذجين لتقسير الدور الذي تقــوم بــهـ المــساندة

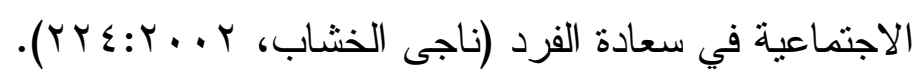
- - النموذج الاول "تموذج الأثر الرئيسي للمساندة:

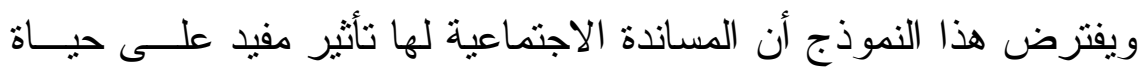

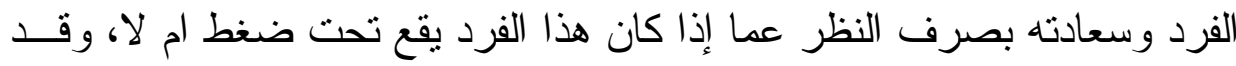

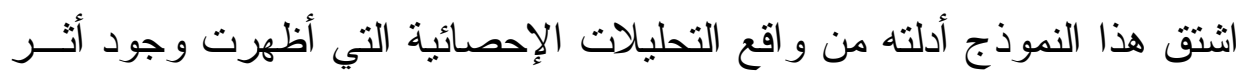

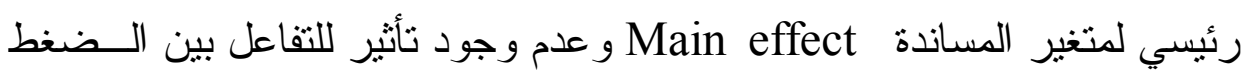

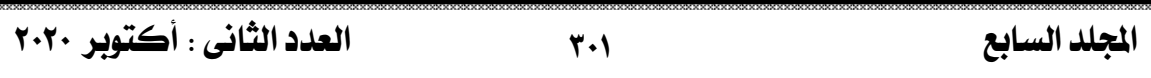


و المساندة مما دعا البعض إلى ان يطلق عليه نموذج الإثر الرئيسي The main

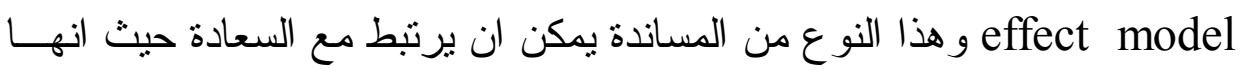

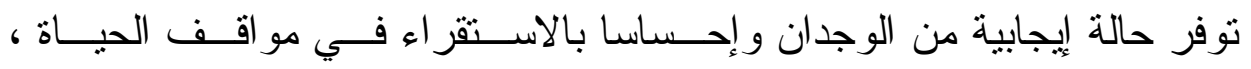

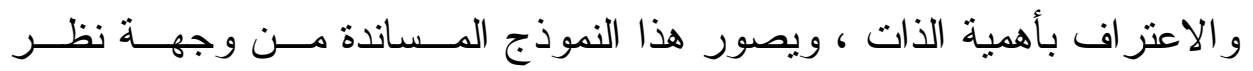

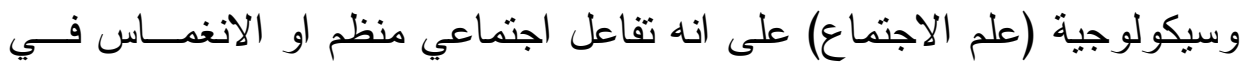

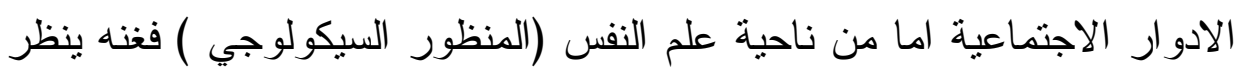

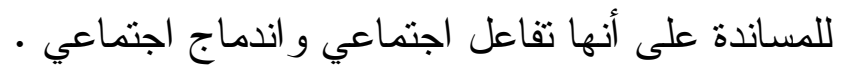

- النموذج الثاني: "نموذج الأثر الو اقي المخفف من الضغط": يفترض هذا النموذج ان المساندة ترتبط بالصحة فقـ بـ بــكل أساســي للأشخاص الذين يقعون تحت ضغط ويُعرف هذا بنموذج التخفيــــ او الحمايــة

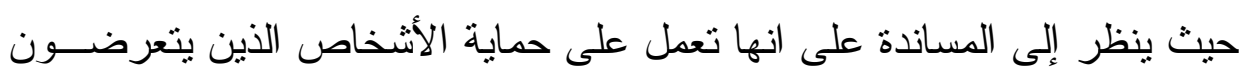

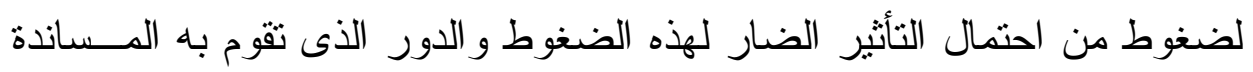

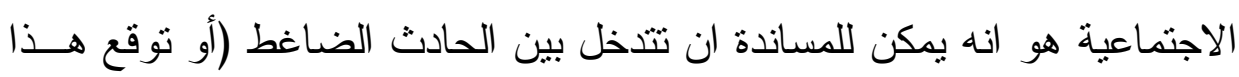

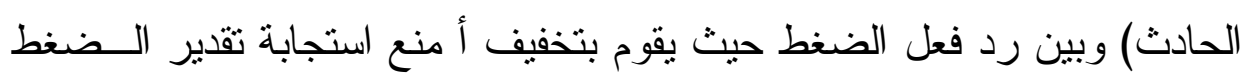

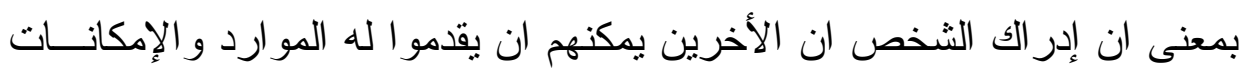

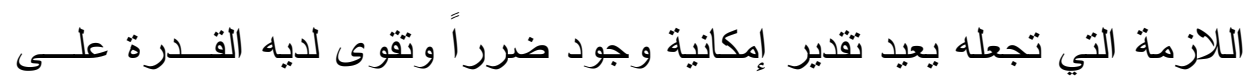

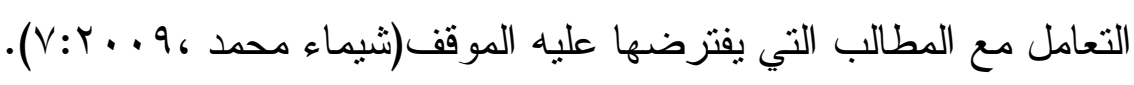
ويفترض هذا النموذج ان أحدث الحياة المثيرة للمشقة التي يتعرض لهـــا

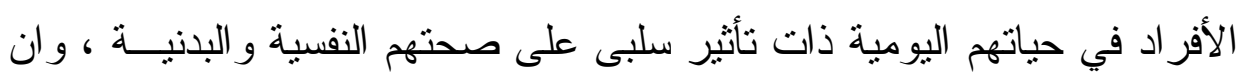

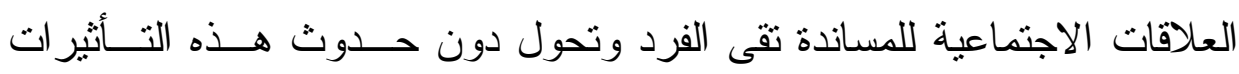

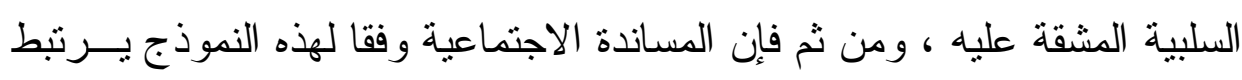


بالصحة لدى الأفر اد الذين يخبرون احداث مثثرة للمشقة ومنـــهـ فــإن العلاقــات الاجتماعية الحميمة تعزز سلوكيات إيجابية او استجابات عصبية غدديه مناســبة التي تحافظ بدور ها على نشاط الجسم الفسيولوجي السليم فــي وجـــه الــضغوط المدمرة و المخاطر الصحية الأخرى التي تهدد صحة الإنسان و عافيته ، بعبــارة

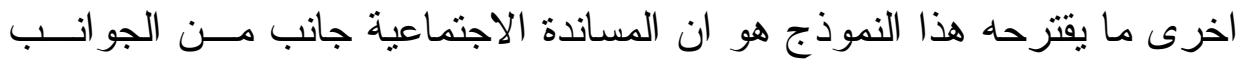
الهامة لعملية إدارة الضغوط ، أبي انه عبارة عن آلية تخفيف الضغوط ـ ـوهذا ما ها يفسر القيمة الوقائية او العلاجية للعلاقات الاجتماعية الحميمة و القويــة ( فنــون

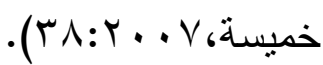

\section{وظائف المساندة الاجتماعية:}

للمساندة الاجتماعية عدة وظائف، فهى تسهم في توفير الر احـــة النفـسية، حيث ان التفاعل الاجتماعى المساند يولد درجة من المشاعر الإيجابية الت تحقق الصحة النفسية وتحقيق المعاناة مــن بعـض الاضـــر ابات النفـسية كـالقلق Anxiety و الاكتئاب Depression و الوحدة النفسية، كما ان ففلها وظيفة نمائية عندما يكون لاى الفرد شبكة من العلاقات الاجتماعية الحميمة التي تساعده على

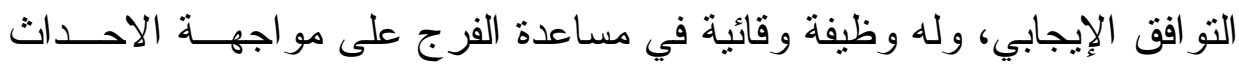

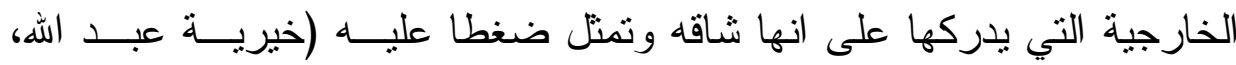
$\cdot(r \leq: r \cdot) \leq$

وتتسم المساندة الاجتماعية بعده وظائف، يمكن إيجاز ها في الفئات الـست

التالية حسب كلا من (Buunk\&Verhoeven,1991;245): - المساعدة المادية (Material Aid) كما تتمثنـل فــي النقــود و الأثــياء المادية . 
- المساعدة السلوكية (Behavioral Assistance) وتثير إلى الــشاركة في المهام و الأعمال المختلفة بالجهد البدني.

- التفاعل الحميم Intimate Interaction) ويسشير بعـض ســلوكيات الإرشاد غير الموجه كإنصات و التعبير عن التقدير، و الرعاية و الفهم. - التوجيه(Guidance) كما يتمنل في تقديم النصيحة، و إعطاء المعلومسـات

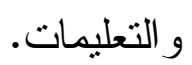
- العائد و المردود (Feedback)، ويعنى إعطاء الفرد مردوداً عن سـلوكه و أفكاره ومشاعره. - التفاعل الاجتماعي الإيجابي (Positive Social Interaction) ويـشير

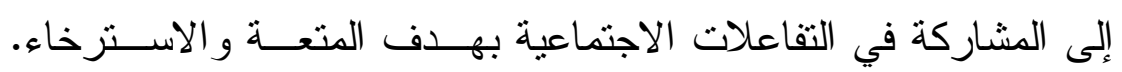
(Bunk,Verhoeven\&1991;245)

ويقسم شاماك وبرويلــي (Shumaker\& Brownall,1984) وظــائف

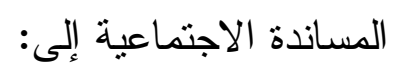

- - وظائف مساندة الصحة: هي تقوى الصحة الــشاملة للجـسم و العقـلـل

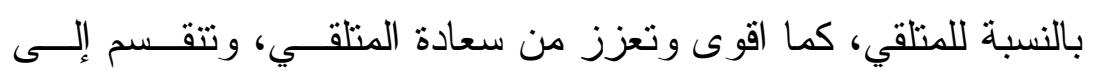

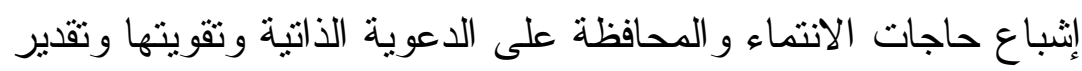

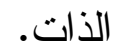

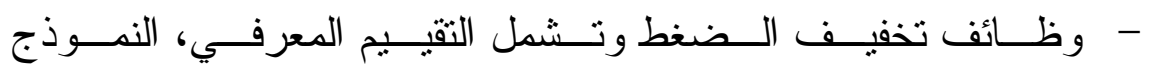
النو عي للمساندة، التكيف، المو اجهة (شيماء محمد، 9 . . ب: 1 (1). 
- أميرة احمد عبده صــلاح (19 (ب): المـسـاندة الاجتماعيــة و علاقتهـــا بالصلابة النفسية لدى عينة من مريضات سرطان الثذى في محافظة رام

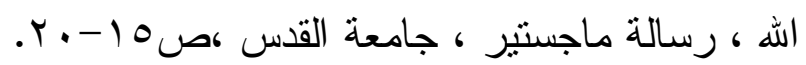

- حنان مجدى صالح (9 . . ب): المساندة الاجتماعية و علاقتها بجودة الحياة لدى مريض السكر المر اهق ، رسالة دكتور اة ، كلية التربية ، جامعــة

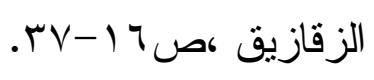

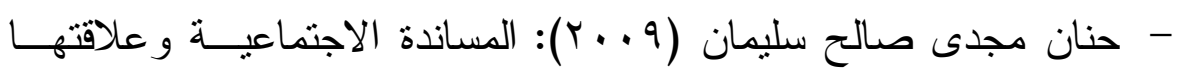
بجودة الحياة لدى مريض السكر المر اهق ، در اسة سيكومترية اكلينيكة ، رسالة ماجستير ، كلية التزبية ، قسم الصحة النفسية ، جامعة ازقـازيق

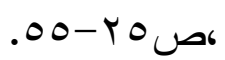

- ر انيا محمد حسين أبو القمصان (Y V V P): المساندة الاجتماعية و علاقتها

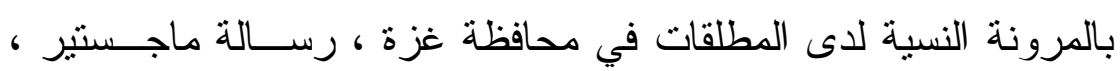
كلية التزبية ، الجامعة الإسلامية ، غزة ،صل ب أ- ب.

- شيماء أحمد محد الديدامونى (9 . . ب): المساندة الاجتماعيـــة وعلاقتهـــا بالموهبة الإبتكارية للمر اهقين ، كلية التربية ، جامعة الزقازيق، صلاهـ .$r$. - عماد محمد مخيمر (997 (1) :الصلابة النفـسية و المـسـاندة الاجتماعيــة كمتغير ات وسيطة في العلاقات بين ضغوط الحياة و أعر اض الإكتئـاب 
لاى شباب الجامعة ، القاهرة، مجلة در اسات نفسية ، المجلد (V)، العدد

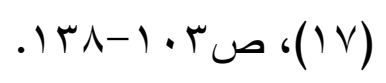

- ماجدة حسين (9 . . ب):المساندة الاجتماعية وعلاقتها بالضغوط النفـسية

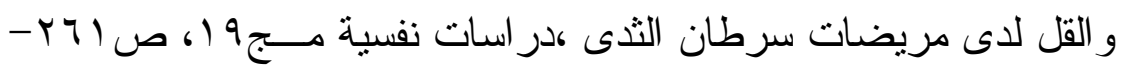

- محمد الثناوى ، محمد عبد الــرحمن (؟99 1): المسـساندة الاجتماعيــة

و الصحة النفسية ، مر اجعة نظرية ودر اسات تطبيقيــة ،ط ا، القــاهرة ، مكتبة الاتجلو المصرية ص r-r.

- هيام صابر شاهين (0. . ب): المساندة الاجتماعية كما يدركها عينة مسن

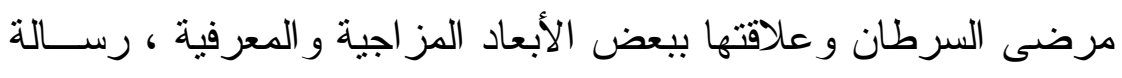

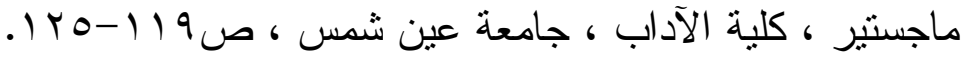

